\title{
The changes in cardiopulmonary resuscitation guidelines: from 2000 to the present
}

\author{
Oh Young Kwon* \\ Department of Medical Education and Medical Humanities, College of Medicine, Kyung Hee University, Seoul, Korea
}

This review aims to determine the changes made in the cardiopulmonary resuscitation (CPR) guidelines from 2000 to the present. The study was mainly undertaken by using International Guidelines from American Heart Association. The main change of CPR was chest compression skill. The guidelines have improved high-quality CPR through the change of chest compression skill. The latest adult CPR guidelines are as follows: (a) push chest quickly (100-120/min), (b) compress appropri- ately $(5-6 \mathrm{~cm}),(\mathrm{c})$ relax chest fully (complete chest recoil), (d) avoid interruption of compression, and (e) avoid hyperventilation. The understanding of the latest CPR skills will be helpful in improving survival rate from sudden cardiac death.

Keywords: Cardiopulmonary resuscitation, Guideline, Cardiac arrest, Chest compression

\section{INTRODUCTION}

The major cause of cardiac arrest (CA) is cardiovascular in origin, and more often than not, it is unpredictable. In about $5 \mathrm{~min}$ after cessation of heartbeat, irrespective of its causes, brain cells start to deteriorate dramatically (Safar, 1986). Many people who experience CA eventually die; however, for survivors of CA, familial or social supports such as rehabilitations are provided because of the neurologic sequelae which can result from hypoxic brain damage (Boyce et al., 2019). So far, the only way to save a victim suffering from CA is cardiopulmonary resuscitation (CPR).

The definition of CPR is a skill that can revive the human body when the process of death begins. Resuscitation Medicine in the field of Emergency Medicine has developed for hundreds of years. In 1767, the first rescue organization named "Amsterdam Rescue Society" has been established in the Netherlands (Bierens, 2017). They have started rescuing drowned people in Amsterdam and saved 150 victims since the past 4 years (Trubuhovich, 2006).

The current methods of CPR were based on the ones formed in the 1950s. The American Academy of Science made the first guidelines for CPR in 1966 (Ad Hoc Committee on Cardiopulmonary
Resuscitation, 1966). After that, two prominent societies, the American Heart Association in the US and the European Resuscitation Council in Europe have improved their own CPR guidelines respectively. These two societies formed the International Liaison Committee on Resuscitation (ILCOR) for the development of international guidelines in 1992. After 8 years, ILCOR created the "International Guidelines 2000 for CPR \& ECC (emergency cardiovascular care)", which became the cornerstone that standardized various CPR methods worldwide. The guidelines are the basis of most currently existing CPR methods that are being used in inhospital or out-of-hospital circumstances. Furthermore, the renewal of the guidelines has been announced every 5 years since 2000 .

The guidelines have basic contents for laypersons as well as advanced contents for healthcare providers (Kleinman et al., 2015; Link et al., 2015). Laypersons are trained globally with basic guidelines in order for the trainees to be able to act as lifesavers. Accordingly, there have been many reports of people who received CPR training successfully resuscitating victims.

The international CPR guidelines have been revised 3 times since 2000, and the latest one was presented in 2015. Several basics in physiologic fundamentals and maneuvers of CPR have changed.
${ }^{\star}$ Corresponding author: Oh Young Kwon (D https://orcid.org/0000-0003-0817-2256 Department of Medical Education and Medical Humanities, College of Medicine, Kyung Hee University, 26 Kyungheedae-ro, Dongdaemun-gu, Seoul 02447, Korea E-mail:koy04@naver.com

Received: October 28, 2019 / Accepted: November 12, 2019
This is an Open Access article distributed under the terms of the Creative Commons Attribution Non-Commercial License (http://creativecommons.org/licenses/by-nc/4.0/) which permits unrestricted non-commercial use, distribution, and reproduction in any medium, provided the original work is properly cited. 
This paper aims to investigate the changes made in the CPR guidelines from 2000 to the present. The author mainly identified the purpose of these changes by examining the guidelines. This paper will be helpful in understanding the latest methods and the highlights of CPR.

\section{INTERNATIONAL GUIDELINES 2000}

The guidelines 2000 was meaningful in itself as the first unified international recommendation for CPR (American Heart Association, International Liaison Committee on Resuscitation, 2000a). It was used as a basis for the next guidelines, "evidence-based resuscitation guidelines", in which updates were supported by the results of resuscitation studies. The "level of evidence" classified each skill of CPR by the results. In other words, there were four levels of classification; (a) definitely recommended, (b) good to very good recommended, (c) fair to good recommended, (d) may be harmful.

The concept of "Chain of Survival" has emerged as a way for higher potential survival rates in patients suffering from CA (American Heart Association, International Liaison Committee on Resuscitation, 2000b). It consisted of four links; (a) early access (emergency call), (b) early CPR, (c) early defibrillation (an electric shock to the victim), and (d) early advanced CPR (in-hospital treatment). Layperson (a witness) had to recognize a victim that passed out and had to make a phone call to the emergency system (911). The provision of subsequent $\mathrm{CPR}$ was strongly related to survival rate. The first three links were the responsibilities of the layperson since several minutes are needed until emergency medical technicians arrive and can attend to the victim. Therefore, the role of the layperson was quite important in a CPR situation. If anyone of these links broke, the survival rate was greatly reduced even with advanced treatments in a hospital such as intubation or epinephrine injection (Cummins et al., 1991).

The chief aspects of CPR procedure were chest compression and mouth-to-mouth breathing (rescue breathing). These two skills have been part of the CPR procedures since the beginning (Trubuhovich, 2006). In the guidelines 2000, chest compression was more highlighted than rescue breathing. The chest compression rate was increased and was unified to 100 times per minute for both adults and children. The rate was based on a human study that reported that greater than 80 compressions showed good outcomes in CA (Kern et al., 1992). The past guideline recommended about 80-100 compressions for adults and children and 120 compressions for infants (American Heart Association, 1992). Many healthcare providers performed inadequate chest compressions of less than 100 following the old recommendation. It was inefficient to supply a sufficient quantity of blood to the brain and the heart. The discrepancy between the compression rate and the age was also resolved.

In these guidelines, the compression-ventilation ratio was fixed on 15:2 at all occasions. The previous recommendation was 5:1 ratio in case of a lone rescuer and 15:2 ratio in case of two rescuers (American Heart Association, 1992). The change in the ratio showed two significances: (a) gave the victim more chest compressions per minute ( $28 \%$ or more) and (b) same compression-ventilation ratio applied regardless of the number of rescuers. If one rescue breathing is performed per five compressions, the interruptions between the compressions occur too frequently during $\mathrm{CPR}$, resulting in decreased coronary artery perfusion (Wik and Steen, 1996). On the other hand, 15 continuous compressions can increase the amount of blood flow to the heart. The aforementioned fixed ratio would be very useful in enlightening the trainees, as well.

Compression depth, rate, and ratio were newly determined. The past rule in chest compression depth was defined as the difference in the height of a rescuer's shoulder by 2.5 to $5 \mathrm{~cm}$ during CPR (American Heart Association, 1992). The standard of compression depth was changed to the depth in a victim's chest and not the shoulder level of a rescuer. A rescuer had to compress an adult chest by 4 to $5 \mathrm{~cm}$ in depth.

For laypersons to easily carry out the processes of checking the breathing and pulse (heartbeat) of the victim, they were modified simply. Checking for breathing may be one of the difficult steps in resuscitation (Parnell and Larsen, 2007). An assessment of breathing consisted of (a) looking at the chest, (b) listening for air escaping, and (c) feeling for the flow of air. Rescue breathing had to be delivered if normal breathing is absent. Furthermore, checking for pulse was a more difficult task than checking for breathing (Dick et al., 2000). In emergency situations that required CPR, it was crucial for healthcare providers to verify carotid artery pulsation (Eberle et al., 1996). However, even finding the artery is difficult for a layperson. The guideline, therefore, advised that a layperson give the victim only chest compressions if there is an absence of normal breathing, coughing, or movement.

The concept of electric treatment to the heart has also changed (European Resuscitation Council, 2000). Providing early defibrillation (arresting the fibrillation of the heart) was the best way to improve survival from sudden cardiac death caused by ventricular tachycardia or ventricular fibrillation (Cummins et al., 1986). Even though the mechanism of defibrillation is not completely under- 
stood, it is well known that normal rhythm can be recovered by stunning the heart with high electric shock (Trayanova, 2006). In previous guidelines, precordial thump (a method that strikes the middle of a victim's sternum) was introduced in order to make sufficient energy that can arrest the heart. However, it was removed due to studies that showed no effect in performing it (Gertsch et al., 1992). Automated external defibrillator (AED) has come into widespread use for defibrillation since the 1990s. The device was designed for lay rescuers. Two significant studies influenced the dissemination of AED. One study conducted in US casinos showed that the use of AED within 5 min on a victim with CA can improve survival (Valenzuela et al., 2000). Another study at airports reported similar results (Caffrey et al., 2002). AEDs have started to be placed in areas with large gatherings of people including airports, high-rise office buildings, housing complexes, recreational facilities, and so on. However, the use of AEDs was not recommended for children under 8 years of age due to the lack of evidence.

\section{INTERNATIONAL GUIDELINES 2005}

Even after the release of the guidelines 2000, incidence and mortality of out-of-hospital sudden CA were very high (Rea et al., 2004). Guidelines 2005 was focused on continuous quality improvement of CPR to raise survival rate of CA (ECC Committee, 2005a). The biggest change made in these guidelines was the increase in the number of consecutive chest compressions. Excellent chest compressions were considered as an essential factor for highquality CPR. In addition, the actual amount of blood going out of the heart (cardiac output) through chest compressions was less than 30\% of that of the normal cardiac output (Duggal et al., 1993). A study on the quality of CPR demonstrated that previously decided compression depth of 4 to $5 \mathrm{~cm}$ was insufficient (Wik et al., 2005). Thus trainees were taught to "push hard, push fast" to put emphasis on the chest compressions (ECC Committee, 2005b). Moreover, rescuers had to be changed every 2 min of compression and rescue breathing in order to avoid exhaustion in rescuers. The compression rate and breathing time were also simplified compared to those of the guidelines 2000. The reason for the simplification was that laypersons did not remember or carry out the exact chest compression and rescue breathing well in following the previous guidelines.

The main focus of the guidelines 2005 was to change the compression-ventilation ratio to 30:2 for sole rescuers of all ages from a ratio of 15:2. The compression rate was doubled compared to the previous standard. The change of the ratio was supported by experimental studies which reported that much more compressions can be beneficial (Berg et al., 2001; Dorph et al., 2004). Interruptions during compression occurred more frequently in 15-compression sets than in 30-compression sets. The interruptions reduced blood flow to the heart and brain, causing the high mortality (Kern et al., 2002). Uninterrupted 30 compressions were more favorable in increasing blood pressure in critical organs. However, the 15:2 ratio was maintained in children up to the start of puberty for 2-rescuer teams. In children and infants, oxygen supply through rescue breathing was as important as chest compressions. The compression rate in the guideline was maintained in approximately 100 per min in all ages.

Another characteristic of the guidelines specified change of rescuers to prevent rescuer fatigue and maximize the effectiveness of chest compressions. Rescuer fatigue was associated with inadequate chest compression depth and rate (Hightower et al., 1995). It was advisable to rotate the compressor every 2 min or every five cycles (5 times of 30:2). Incomplete chest wall recoil (chest wall not rising fully after compression) was also common, especially when a rescuer was fatigued (ECC Committee, 2005c). Incomplete recoil decreased the venous return to the heart due to higher intrathoracic pressures than when recoil is complete.

The criteria for respiration were also simplified. According to the guidelines, layperson could start to compress the chest of a victim immediately without rescue breathing if the victim had no respiration and movement. The time duration of one breathing was set to $1 \mathrm{sec}$. The proper volume of breathing was determined to be appropriate when the chest of the victim rises after rescue breathing. In the previous guidelines, there was no specific volume for rescue breathing and no clear standard for checking respiration. If too much air is supplied, it could enter the stomach and not into the lungs of the victim. Gastric inflation can induce regurgitation and aspiration due to diaphragm elevation, which worsens the prognosis of the patient (American Heart Association, 2000b). Hyperventilation leads to increased intrathoracic pressure, which prevents blood from returning to the heart during CPR (Aufderheide et al., 2004). Furthermore, hyperoxia that results from hyperventilation also correlates with high mortality and poor neurological outcomes (Llitjos et al., 2016). For several reasons, the importance of respiration has gradually diminished compared to the past guidelines.

The use of adult dose electric shock for children was newly recommended. Defibrillation had to be required for CA in children, but lower electrical energy was applied because the pediatric heart cells were vulnerable to higher electrical energy of adult doses. 
There must be pediatric electrode pads (to reduce the delivered energy to a dose suitable for children) in every AEDs, but they were usually not equipped together. Even if there were no pediatric pads, it was highly recommended to use an adult pad over risking negative effects from high electrical energy. This recommendation was predicated by a study which reported that adult electric dose would be useful for children (Jorgenson et al., 2002). However, AED use for infants (less than 1 year) was still not recommend.

\section{INTERNATIONAL GUIDELINES 2010}

Guidelines 2010 focused on facilitating the involvement of witnesses in CPR (American Heart Association, 2010). For that, the initial sequence of CPR was considerably simplified from collapse to chest compression. Furthermore, through promotion of high-quality CPR since 2005, the importance of chest compression still remained emphasized. One more link was added to the existing four links of the "Chain of Survival" to enhance survival rate and neurological outcomes of survivors from CA (Peberdy et al., 2010). The use of AEDs on infants was newly confirmed (Link et al., 2010). The confirmation depended on previous studies which reported that infant arrest victims who received high energy shock survived with minimal myocardial damage and good neurological outcome (König et al., 2005; Zafari et al., 2004).

The main alteration of the guidelines was the change of overall CPR sequence. The past classical sequence called "A-B-C" (airwaybreathing-compression) was changed to "C-A-B." Chest compression was the most critical and primary skill in CPR. The start with airway in the past sequence was based on the modern version of ventilation-oriented CPR for drowning victims. The "A-B-C" method had a disadvantage of delaying too much time until chest compression. The common cause of witnessed CA in victims was mainly cardiac dysrhythmia; therefore, blood supply to the vital organs by chest compression had to precede ventilation. Shortening time to chest compression increased the chance of return of spontaneous circulation (ROSC).

The "A-B-C" method also made it difficult for laypersons to engage as rescuers. They felt burdensome or reluctant to give rescue breathing to a victim whom they have never met before (Hew et al., 1997). Laypersons, in particular, could not easily recognize whether the victim showed normal breathing or not. Occasional gasps, which cannot supply sufficient oxygen, are misinterpreted by rescuers as normal breathing (Ruppert et al., 1999). Therefore, in order to avoid the confusion, three steps of breathing check (look, listen, and feel) were deleted from the guidelines.

As with the past guidelines, high-quality chest compression was maintained. At first, a compression depth of at least $5 \mathrm{~cm}$ was recommended. Insufficient sternal depth by the previous rule (4-5 $\mathrm{cm}$ ) could generate unsatisfactory cardiac output and could prove fatal (Abella et al., 2005). Moreover, rescuers had a tendency not to compress deeply due to fear of causing rib or sternal fractures (Lederer et al., 2004). The rate of compression was changed from approximately 100 compressions per min to at least 100 for all ages. The rate below 100 per min was not recommended for all laypersons and healthcare providers. It was based on the study showing that survival rate improved when 120 consecutive chest compressions were done (Christenson et al., 2009).

Complete chest wall recoil and minimizing interruptions in chest compression were re-emphasized for high-quality CPR. Incomplete recoil caused by immediate compression without chest rising resulted in the depression of coronary arterial perfusion and cardiac output (Yannopoulos et al., 2005). The experimental study proved that continuous chest compression was the only way to establish sufficient cerebral and coronary blood flow (Ewy, 2005). One study had even suggested that the hand should be lifted slightly but completely off the chest at the end of each compression (Aufderheide et al., 2005).

The addition of one link strengthened the "Chain of Survival." The link named "integrated postcardiac arrest care" was added after the fourth link, "effective advanced life support." It defined the whole treatment after recovery from CA in a hospital. Most deaths occurred within the first $24 \mathrm{hr}$ even if the patients had spontaneous circulation (Laurent et al., 2002). Immediately after recovery from $\mathrm{CA}$, the patients were managed for optimized body temperature (about $34^{\circ} \mathrm{C}$ ), adequate oxygenation, and appropriate blood pressure for $24 \mathrm{hr}$. The postcardiac arrest care was strongly related to mortality (Callaway et al., 2010). For conservation of brain function, this care was a crucial therapeutic method in unconscious patients after ROSC (Castrejón et al, 2009). In addition, minimizing neurological sequelae after recovery is considered as an important societal and individual issue.

\section{INTERNATIONAL GUIDELINES 2015}

The newest CPR guidelines were made by a total of 250 evidence reviewers from 39 countries in 2015 (American Heart Association, 2015). Although the number of experts was similar with that of the previous, 10 more countries participated for the guidelines 2015. There were several changes, but not as much com- 
pared to 2010. Quality improvement through proper chest compressions was still the main topic in CPR. Particularly, use of social media was recommended as a means of notifying potential rescuers nearby by Emergency Medical Dispatchers (people who receive emergency calls). This way of notification was mainly attributed to the widespread use of smartphones (Ringh et al., 2015).

The most important change of guidelines 2015 was the rate of chest compression. The rate was increased to between 100 and 120 compressions per minute, meaning rescuers should compress almost 2 times a second. Therefore, rescuers were pressured to perform faster compressions. The observational human studies evaluated that the compression rate was related to CA survival to hospital discharge, percentage of ROSC, and physiologic features of the patient (Idris et al., 2012; Idris et al., 2015). The next guidelines are likely to encourage more than 120 compressions. However, the rate of over 120 compressions could lead to shallow depth compressions as time passes thus, further studies should be done to analyze the optimal rate of compression (Idris et al., 2015).

Another change was to define the maximum value of compression depth. A depth of $5 \mathrm{~cm}$ was favorable for good outcomes from the victims in previous studies (Vadeboncoeur et al., 2014). However, it was proved that a depth of greater than $6 \mathrm{~cm}$ could cause compression-induced injuries such as fractures of the sternum or ribs (Hellevuo et al., 2013). The best range of compression depth was advised to be 5 to $6 \mathrm{~cm}$. The slogan "Push Hard," which was emphasized in guidelines 2005 and 2010, seemed to have disap- peared for that reason. A more detailed range of the depth must be specified for laypersons because it is practically difficult to push the chest to this depth in reality.

"Compression-Only CPR" was strongly recommended for laypersons once more. The reasons being that it can be easily provided by untrained people and the decline of oxygen supply that occurs even when rescue breathing was skipped was of no great concern (Hüpfl et al., 2010). In early stage of CA, a sufficient amount of oxygen exists in the spare spaces of the lungs, which can be supplied to the tissue even through chest compressions for a few minutes (Iwami et al., 2007). Therefore, CPR without ventilation was a feasible method for laypersons until the arrival of emergency medical technicians in urban situations (Svensson et al., 2010). But, trained laypersons should still provide rescue breathing in case of respiratory arrest during CPR (e.g., asphyxia, drowning, trauma, intoxication, and pediatric CPR) (Kleinman et al., 2015).

As the survival rate of CA patients did not increase despite the developments in medical science, guidelines 2015 concentrated more on thorough resuscitation education. Furthermore, contextual education using applicable training scenarios was emphasized to learners (Bhanji et al., 2015). It should be necessary for the learners to do repetitive drills of the CPR skills with explanation, as well (Motola et al., 2013). What's more, considerable hands-on training must be demanded to accomplish performance of psychomotor skills (Lynch et al., 2005).

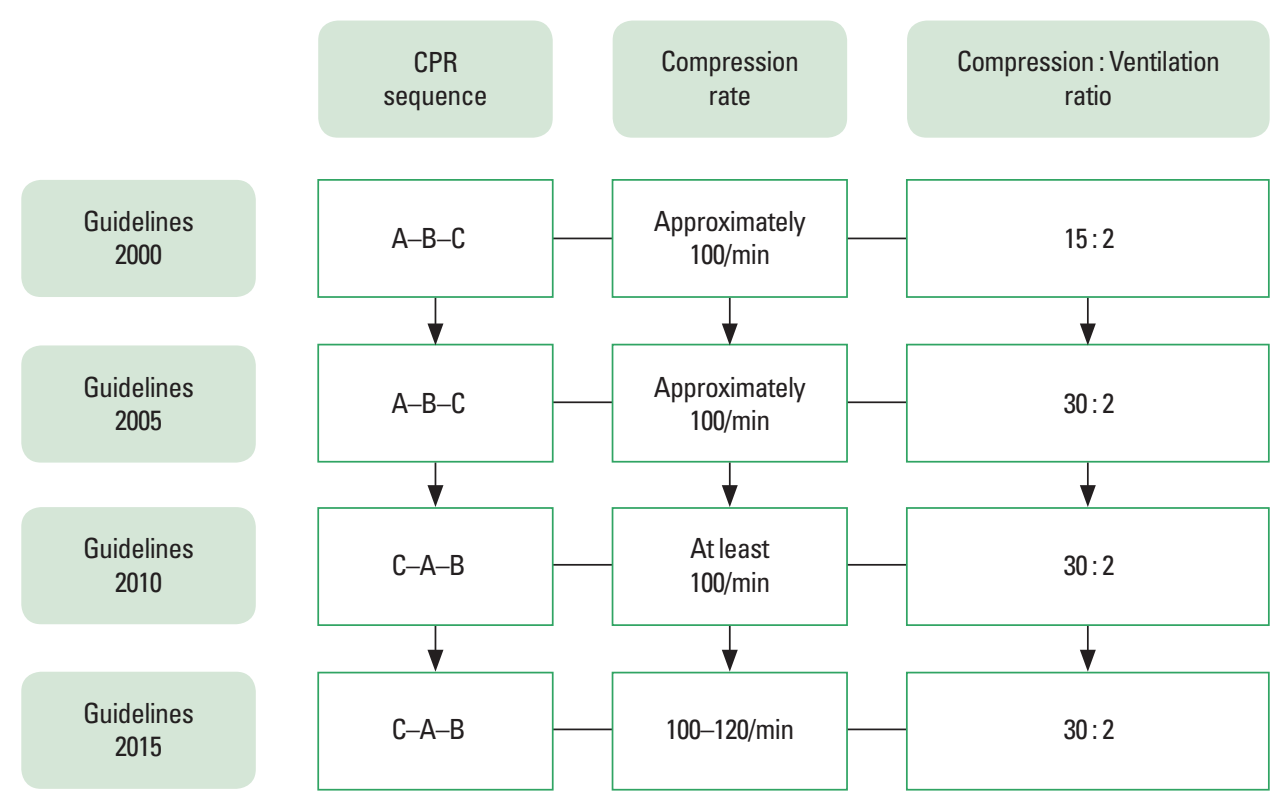

Fig. 1. The changes of highlights in CPR from guidelines 2000 to 2015. CPR, cardiopulmonary resuscitation; A, airway; B, breathing; C, compression. 


\section{CONCLUSIONS}

The global incidence of sudden CA is known to be 24 to 186 per 100,000 person-years. Despite advancements in medical technology, the number of $\mathrm{CA}$ is high due to the aging of the population and the high prevalence of heart disease (Berdowski et al., 2010). Unlike other diseases, the survival rate is still less than $10 \%$ (Chan et al., 2014). However, numerous researches about resuscitation medicine have been studied, which became a driving force for the revision of the guidelines every 5 years. The frequency of CPR education for the public and healthcare providers is increasing, and the survival rates are increasing gradually (Chan et al., 2014). Nonetheless, medical scientists have not yet found the most proper CPR method to perform in victims with arrested hearts.

The main highlights of consequence are the changes related to chest compression. The guidelines have revised that the rescuers should compress the chest quickly and adequately. The rescuers should also minimize the time of hands off the chest for continuous compression. The latest $\mathrm{CPR}$ sequence was changed to do the chest compressions first and not the rescue breathing. The significance of ventilation during adult CPR has been weakened gradually, hence laypersons were educated with compression-only method. Also, there is a strong recommendation for the use of AEDs in public spaces and it is closely correlated with ROSC.

In conclusion, the changes of highlights in CPR from guidelines 2000 to 2015 are shown in Fig. 1. The latest adult CPR guidelines are as follows: (a) push fast (100-120/min), (b) compress appropriately $(5-6 \mathrm{~cm})$, (c) relax the chest fully (complete chest recoil) (d) avoid interruption of compression, and (e) avoid hyperventilation. If one does not remember the above details in a situation that necessitates $\mathrm{CPR}$, it would be best to give the victim two chest compressions per second only after emergency call.

\section{CONFLICT OF INTEREST}

No potential conflict of interest relevant to this article was reported.

\section{REFERENCES}

Abella BS, Alvarado JP, Myklebust H, Edelson DP, Barry A, O’Hearn N, Vanden Hoek TL, Becker LB. Quality of cardiopulmonary resuscitation during in-hospital cardiac arrest. JAMA 2005;293:305-310.

Ad Hoc Committee on Cardiopulmonary Resuscitation. Cardiopulmonary resuscitation: statement by the Ad Hoc Committee on Cardio- pulmonary Resuscitation of the Division of Medical Sciences, National Academy of Sciences, National Research Council. JAMA 1966;198: 372-379.

American Heart Association. 2010 American Heart Association Guidelines for cardiopulmonary resuscitation and emergency cardiovascular care science. Circulation 2010;122(18 Suppl 3):S1-946.

American Heart Association. 2015 American Heart Association Guidelines update for cardiopulmonary resuscitation and emergency cardiovascular care. Circulation 2015;132(Suppl 2):S1-589.

American Heart Association. Guidelines for cardiopulmonary resuscitation emergency cardiac care. JAMA 1992;268:2212-2302.

American Heart Association, International Liaison Committee on Resuscitation. Guidelines 2000 for cardiopulmonary resuscitation and emergency cardiovascular care. Part 1: introduction to the international guidelines 2000 for CPR and ECC: a consensus on science. Circulation 2000a;102(8 Suppl):I1-11.

American Heart Association, International Liaison Committee on Resuscitation. Guidelines 2000 for cardiopulmonary resuscitation and emergency cardiovascular care. Part 3: adult basic life support. Circulation 2000b;102(8 Suppl):I22-59.

Aufderheide TP, Pirrallo RG, Yannopoulos D, Klein JP, von Briesen C, Sparks CW, Deja KA, Conrad CJ, Kitscha DJ, Provo TA, Lurie KG. Incomplete chest wall decompression: a clinical evaluation of CPR performance by EMS personnel and assessment of alternative manual chest compression-decompression techniques. Resuscitation 2005;64: 353-362.

Aufderheide TP, Sigurdsson G, Pirrallo RG, Yannopoulos D, McKnite S, von Briesen C, Sparks CW, Conrad CJ, Provo TA, Lurie KG. Hyperventilation-induced hypotension during cardiopulmonary resuscitation. Circulation 2004;109:1960-1965.

Berdowski J, Berg RA, Tijssen JG, Koster RW. Global incidences of out-ofhospital cardiac arrest and survival rates: systematic review of 67 prospective studies. Resuscitation 2010;81:1479-1487.

Berg RA, Sanders AB, Kern KB, Hilwig RW, Heidenreich JW, Porter ME, Ewy GA. Adverse hemodynamic effects of interrupting chest compressions for rescue breathing during cardiopulmonary resuscitation for ventricular fibrillation cardiac arrest. Circulation 2001;104:2465-2470.

Bhanji F, Donoghue AJ, Wolff MS, Flores GE, Halamek LP, Berman JM, Sinz EH, Cheng A. Part 14: Education: 2015 American Heart Association Guidelines update for cardiopulmonary resuscitation and emergency cardiovascular care. Circulation 2015;132(18 Suppl 2):S561-573.

Bierens JJLM. The Amsterdam-based Maatschappij tot Redding van Drenkelingen 1767-2017: guiding drowning resuscitation during 250 years. Resuscitation 2017;120:A1-4.

Boyce LW, Goossens PH, Moulaert VR, Pound G, van Heugten CM. Out- 
of-hospital cardiac arrest survivors need both cardiological and neurological rehabilitation! Curr Opin Crit Care 2019;25:240-243.

Caffrey SL, Willoughby PJ, Pepe PE, Becker LB. Public use of automated external defibrillators. N Engl J Med 2002;347:1242-1247.

Callaway CW, Schmicker R, Kampmeyer M, Powell J, Rea TD, Daya MR, Aufderheide TP, Davis DP, Rittenberger JC, Idris AH, Nichol G; Resuscitation Outcomes Consortium (ROC) Investigators. Receiving hospital characteristics associated with survival after out-of-hospital cardiac arrest. Resuscitation 2010;81:524-529.

Castrejón S, Cortés M, Salto ML, Benittez LC, Rubio R, Juárez M, López de Sá E, Bueno H, Sánchez PL, Fernández Avilés F. Improved prognosis after using mild hypothermia to treat cardiorespiratory arrest due to a cardiac cause: comparison with a control group. Rev Esp Cardiol 2009;62:733-741.

Chan PS, McNally B, Tang F, Kellermann A; CARES Surveillance Group. Recent trends in survival from out-of-hospital cardiac arrest in the United States. Circulation 2014;130:1876-1882.

Christenson J, Andrusiek D, Everson-Stewart S, Kudenchuk P, Hostler D, Powell J, Callaway CW, Bishop D, Vaillancourt C, Davis D, Aufderheide TP, Idris A, Stouffer JA, Stiell I, Berg R; Resuscitation Outcomes Consortium Investigators. Chest compression fraction determines survival in patients with out-of-hospital ventricular fibrillation. Circulation 2009;120:1241-1247.

Cummins RO, Eisenberg MS, Stults KR. Automatic external defibrillators: clinical issues for cardiology. Circulation 1986;73:381-385.

Cummins RO, Ornato JP, Thies WH, Pepe PE. Improving survival from sudden cardiac arrest: the "chain of survival" concept. A statement for health professionals from the Advanced Cardiac Life Support Subcommittee and the Emergency Cardiac Care Committee, American Heart Association. Circulation 1991;83:1832-1847.

Dick WF, Eberle B, Wisser G, Schneider T. The carotid pulse check revisited: what if there is no pulse? Crit Care Med 2000;28(11 Suppl):N183185.

Dorph E, Wik L, Strømme TA, Eriksen M, Steen PA. Oxygen delivery and return of spontaneous circulation with ventilation:compression ratio 2:30 versus chest compressions only CPR in pigs. Resuscitation 2004; 60:309-318.

Duggal C, Weil MH, Gazmuri RJ, Tang W, Sun S, O'Connell F, Ali M. Regional blood flow during closed-chest cardiac resuscitation in rats. J Appl Physiol (1985) 1993;74:147-152.

Eberle B, Dick WF, Schneider T, Wisser G, Doetsch S, Tzanova I. Checking the carotid pulse check: diagnostic accuracy of first responders in patients with and without a pulse. Resuscitation 1996;33:107-116.

ECC Committee, Subcommittees and Task Forces of the American Heart Association. 2005 American Heart Association Guidelines for cardio- pulmonary resuscitation and emergency cardiovascular care. Circulation 2005a;112(24 Suppl):IV1-203.

ECC Committee, Subcommittees and Task Forces of the American Heart Association. 2005 American Heart Association Guidelines for cardiopulmonary resuscitation and emergency cardiovascular care. Part 3: overview of CPR. Circulation 2005b;112(24 Suppl):IV12-18.

ECC Committee, Subcommittees and Task Forces of the American Heart Association. 2005 American Heart Association Guidelines for cardiopulmonary resuscitation and emergency cardiovascular care. Part 4: adult basic life support. Circulation 2005c;112(24 Suppl):IV19-34.

European Resuscitation Council. Part 4: the automated external defibrillator: key link in the chain of survival. Resuscitation 2000;46:73-91.

Ewy GA. Cardiocerebral resuscitation: the new cardiopulmonary resuscitation. Circulation 2005;111:2134-2142.

Gertsch M, Hottinger S, Hess T. Serial chest thumps for the treatment of ventricular tachycardia in patients with coronary artery disease. Clin Cardiol 1992;15:181-188.

Hellevuo H, Sainio M, Nevalainen R, Huhtala H, Olkkola KT, Tenhunen J, Hoppu S. Deeper chest compression - more complications for cardiac arrest patients? Resuscitation 2013;84:760-765.

Hew P, Brenner B, Kaufman J. Reluctance of paramedics and emergency medical technicians to perform mouth-to-mouth resuscitation. J Emerg Med 1997;15:279-284.

Hightower D, Thomas SH, Stone CK, Dunn K, March JA. Decay in quality of closed-chest compressions over time. Ann Emerg Med 1995;26: 300-303.

Hüpfl M, Selig HF, Nagele P. Chest-compression-only versus standard cardiopulmonary resuscitation: a meta-analysis. Lancet 2010;376:15521557.

Idris AH, Guffey D, Aufderheide TP, Brown S, Morrison LJ, Nichols P, Powell J, Daya M, Bigham BL, Atkins DL, Berg R, Davis D, Stiell I, Sopko G, Nichol G; Resuscitation Outcomes Consortium (ROC) Investigators. Relationship between chest compression rates and outcomes from cardiac arrest. Circulation 2012;125:3004-3012.

Idris AH, Guffey D, Pepe PE, Brown SP, Brooks SC, Callaway CW, Christenson J, Davis DP, Daya MR, Gray R, Kudenchuk PJ, Larsen J, Lin S, Menegazzi JJ, Sheehan K, Sopko G, Stiell I, Nichol G, Aufderheide TP; Resuscitation Outcomes Consortium Investigators. Chest compression rates and survival following out-of-hospital cardiac arrest. Crit Care Med 2015;43:840-848.

Iwami T, Kawamura T, Hiraide A, Berg RA, Hayashi Y, Nishiuchi T, Kajino K, Yonemoto N, Yukioka H, Sugimoto H, Kakuchi H, Sase K, Yokoyama $\mathrm{H}$, Nonogi $\mathrm{H}$. Effectiveness of bystander-initiated cardiac-only resuscitation for patients with out-of-hospital cardiac arrest. Circulation 2007;116:2900-2907. 
Jorgenson D, Morgan C, Snyder D, Griesser H, Solosko T, Chan K, Skarr T. Energy attenuator for pediatric application of an automated external defibrillator. Crit Care Med 2002;30(4 Suppl):S145-147.

Kern KB, Hilwig RW, Berg RA, Sanders AB, Ewy GA. Importance of continuous chest compressions during cardiopulmonary resuscitation: improved outcome during a simulated single lay-rescuer scenario. Circulation 2002;105:645-649.

Kern KB, Sanders AB, Raife J, Milander MM, Otto CW, Ewy GA. A study of chest compression rates during cardiopulmonary resuscitation in humans. The importance of rate-directed chest compressions. Arch Intern Med 1992;152:145-149.

Kleinman ME, Brennan EE, Goldberger ZD, Swor RA, Terry M, Bobrow BJ, Gazmuri RJ, Travers AH, Rea T. Part 5: adult basic life support and cardiopulmonary resuscitation quality: 2015 American Heart Association Guidelines Update for Cardiopulmonary Resuscitation and Emergency Cardiovascular Care. Circulation 2015;132(18 Suppl 2):S414-435.

König B, Benger J, Goldsworthy L. Automatic external defibrillation in a 6 year old. Arch Dis Child 2005;90:310-311.

Laurent I, Monchi M, Chiche JD, Joly LM, Spaulding C, Bourgeois B, Cariou A, Rozenberg A, Carli P, Weber S, Dhainaut JF. Reversible myocardial dysfunction in survivors of out-of-hospital cardiac arrest. J Am Coll Cardiol 2002;40:2110-2116.

Lederer W, Mair D, Rabl W, Baubin M. Frequency of rib and sternum fractures associated with out-of-hospital cardiopulmonary resuscitation is underestimated by conventional chest X-ray. Resuscitation 2004;60: $157-162$.

Link MS, Atkins DL, Passman RS, Halperin HR, Samson RA, White RD, Cudnik MT, Berg MD, Kudenchuk PJ, Kerber RE. Part 6: electrical therapies: automated external defibrillators, defibrillation, cardioversion, and pacing: 2010 American Heart Association Guidelines for cardiopulmonary resuscitation and emergency cardiovascular care. Circulation 2010;122(18 Suppl 3):S706-719.

Link MS, Berkow LC, Kudenchuk PJ, Halperin HR, Hess EP, Moitra VK, Neumar RW, O'Neil BJ, Paxton JH, Silvers SM, White RD, Yannopoulos D, Donnino MW. Part 7: adult advanced cardiovascular life support: 2015 American Heart Association Guidelines update for cardiopulmonary resuscitation and emergency cardiovascular care. Circulation 2015;132(18 Suppl 2):S444-464.

Llitjos JF, Mira JP, Duranteau J, Cariou A. Hyperoxia toxicity after cardiac arrest: what is the evidence? Ann Intensive Care 2016;6:23.

Lynch B, Einspruch EL, Nichol G, Becker LB, Aufderheide TP, Idris A. Effectiveness of a 30-min CPR self-instruction program for lay responders: a controlled randomized study. Resuscitation 2005;67:31-43.

Motola I, Devine LA, Chung HS, Sullivan JE, Issenberg SB. Simulation in healthcare education: a best evidence practical guide. AMEE Guide
No. 82. Med Teach 2013;35:e1511-1530.

Parnell MM, Larsen PD. Poor quality teaching in lay person CPR courses. Resuscitation 2007;73:271-278.

Peberdy MA, Callaway CW, Neumar RW, Geocadin RG, Zimmerman JL, Donnino M, Gabrielli A, Silvers SM, Zaritsky AL, Merchant R, Vanden Hoek TL, Kronick SL; American Heart Association. Part 9: post-cardiac arrest care: 2010 American Heart Association Guidelines for Cardiopulmonary Resuscitation and Emergency Cardiovascular Care. Circulation 2010;122(18 Suppl 3):S768-786.

Rea TD, Eisenberg MS, Sinibaldi G, White RD. Incidence of EMS-treated out-of-hospital cardiac arrest in the United States. Resuscitation 2004; 63:17-24

Ringh M, Rosenqvist M, Hollenberg J, Jonsson M, Fredman D, Nordberg P, Järnbert-Pettersson H, Hasselqvist-Ax I, Riva G, Svensson L. Mobile-phone dispatch of laypersons for CPR in out-of-hospital cardiac arrest. N Engl J Med 2015;372:2316-2325.

Ruppert M, Reith MW, Widmann JH, Lackner CK, Kerkmann R, Schweiberer L, Peter K. Checking for breathing: evaluation of the diagnostic capability of emergency medical services personnel, physicians, medical students, and medical laypersons. Ann Emerg Med 1999;34:720729.

Safar P. Cerebral resuscitation after cardiac arrest: a review. Circulation 1986;74(6 Pt 2):IV138-153.

Svensson L, Bohm K, Castrèn M, Pettersson H, Engerström L, Herlitz J, Rosenqvist M. Compression-only CPR or standard CPR in out-of-hospital cardiac arrest. N Engl J Med 2010;363:434-442.

Trayanova N. Defibrillation of the heart: insights into mechanisms from modelling studies. Exp Physiol 2006;91:323-337.

Trubuhovich RV. History of mouth-to-mouth rescue breathing. Part 2: the 18th century. Crit Care Resusc 2006;8:157-171.

Vadeboncoeur T, Stolz U, Panchal A, Silver A, Venuti M, Tobin J, Smith G, Nunez M, Karamooz M, Spaite D, Bobrow B. Chest compression depth and survival in out-of-hospital cardiac arrest. Resuscitation 2014;85: 182-188.

Valenzuela TD, Roe DJ, Nichol G, Clark LL, Spaite DW, Hardman RG. Outcomes of rapid defibrillation by security officers after cardiac arrest in casinos. N Engl J Med 2000;343:1206-1209.

Wik L, Kramer-Johansen J, Myklebust H, Sørebø H, Svensson L, Fellows B, Steen PA. Quality of cardiopulmonary resuscitation during out-ofhospital cardiac arrest. JAMA 2005;293:299-304.

Wik L, Steen PA. The ventilation/compression ratio influences the effectiveness of two rescuer advanced cardiac life support on a manikin. Resuscitation 1996;31:113-119.

Yannopoulos D, McKnite S, Aufderheide TP, Sigurdsson G, Pirrallo RG, Benditt D, Lurie KG. Effects of incomplete chest wall decompression 
during cardiopulmonary resuscitation on coronary and cerebral perfusion pressures in a porcine model of cardiac arrest. Resuscitation 2005;64:363-372.

Zafari AM, Zarter SK, Heggen V, Wilson P, Taylor RA, Reddy K, Backs- cheider AG, Dudley SC Jr. A program encouraging early defibrillation results in improved in-hospital resuscitation efficacy. J Am Coll Cardiol 2004;44:846-852. 